\title{
Predicting The Tensile Properties Of Woven Kenaf/Polyethylene terephthalate (PET)Fiber Reinforced Polyoxymethylene (POM) Hybrid Laminate Composite
}

\author{
${ }^{1}$ Yakubu Dan-mallam, ${ }^{2}$ Mohamad Z. Abdullah, ${ }^{3}$ Puteri S. M. MegatYusoff \\ ${ }^{1,2,3}$ Department of Mechanical EngineeringUniversitiTeknologi PETRONAS
}

\begin{abstract}
The analytical design of the hybrid composite predicts its tensile properties at different fiber orientation using classical lamination theory. The critical volume fraction of the high elongation fiberyields 0.39 which defines the composite of minimum strength. The high elongation fiber (PET) contributes more in raising the hybrid composite strengthwhile the low elongation fiber (Kenaf) increases the composite modulus more inthe longitudinal direction. Six layers hybrid composite laminates were analyzed. The stacking sequence used was symmetric angle ply $\left(0^{\circ}, 45^{\circ}, 90^{\circ}\right)$ with an overall thickness of $12 \mathrm{~mm}$.The thermal expansion coefficient of the laminate increases more than that of the individual ply. The overall analytical results confirm that thehybrid composite tensile properties haveincreased significantly as compared to single fiber reinforced composite.
\end{abstract}

Key Words: Composite, Hybrid, Laminate, Ply,Matrix, fiber, Tensile, Strength

\section{Introduction:}

Composite materials are widely used in automobile and aircraft industry and have allowed engineers to overcome some obstacles such as corrosion, wear and porosity. The use of natural fiber has over the years gained acceptance in the production of engineering construction materials because of its convenient renewability, biodegradability and ease of fabrication [1].

The growing interest in the use of natural fibers has made engineers to come up with a new design of using two reinforcements in a matrix to produce a Hybrid composite. The hybrid composite offers a range of properties that cannot be achieved when single reinforcement is used and potentially reduce the cost of materials by careful selection of reinforcing fibers. Normally one of the fires in a hybrid composite has a higher elastic modulus than the other. The high elastic modulus fiber provides the stiffness and load bearing quality while the low modulus fiber makes the composite more damage tolerant and keeps the material cost low [2].

\section{Background}

Most natural fibers are naturally discontinues which makes it difficult to perform in high strength applications. This obstacle has been overcome with the development of a twist less natural fiber yarn by a UK based consortium [3]. The research was co-founded by a UK technology strategy board with the mandate to develop high performance natural fiber thermoplastic composite materials for semi structural and structural applications. With the successful development of the materials, the materials were launched commercially with the name Biotex and are available in commingled flax/PP and commingled flax/PLA. Commingled fabrics and yarns containing natural fiber and thermoplastic were developed. The thermoplastic melts on heating to form the matrix.

The demand for woven fabric composite is increasing tremendously due to simple processing technique, acceptable mechanical and physical properties and lower cost of production [4]. Woven fiber reinforced composite offers superior balanced properties in the fabric plane than unidirectional lamina composite. The weaving of the fibers provides a good mechanical interlocking with the matrix which increases strength that cannot be achieved by fiber matrix adhesion. The failure mode of the composite will require the breakage of the fibers since fiber pullout cannot be achieved with high strength woven fabric composite.

Pothanet al. [5] studied the mechanical properties of woven sisal in a polyester matrix using three different architectures of weave (Twill, Plane and Mat). The production process used was resin transfer molding with reference to resin viscosity, applied pressure and weave architecture. The results of his findings suggest that weaving architecture and fiber content have a significant effect on the composite mechanical properties.

The study of the mechanical properties of woven pseudo stem banana fiber and epoxy composite was carried out by Maleque et al. [6]. The results of tensile test showed that the ultimate strength of the banana/epoxy composite increased from $45 \mathrm{MPa}$ to $47 \mathrm{MPa}$ when compared to the un-reinforced epoxy. The young modulus increases from $1300 \mathrm{MPa}$ to $1850 \mathrm{MPa}$ and the flexural strength increased from $45 \mathrm{MPa}$ to 75 
MPa. The result from scanning electron microscopy (SEM) shows that the banana fiber has the ductile type of failure with minimum plastic deformation.

The mechanical properties of two self reinforced polypropylene (SRPP) and glass fiber reinforced Polypropylene (GFPP) hybrid laminate composite was investigated [7]. The aim was to see the possibility of combining SRPP and GRPP in a laminate to achieve a light weight hybrid composite. The first SRPP was supplied in the form of a continues roll cross ply $\left(0^{\circ} / 90^{\circ}\right)$ woven fabric with a nominal thickness of $0.3 \mathrm{~mm}$. The second SRPP was supplied in the form of continuing cross ply $\left(0^{\circ} / 90^{\circ}\right)$ woven roll in the form of flat plates with nominal thicknesses of $3 \mathrm{~mm}$ and $0.3 \mathrm{~mm}$ respectively. Nine different laminates were produced in the order A, $\mathrm{B}, \mathrm{C}$ to $\mathrm{J}$. All the laminates were produced by compression molding in a hydraulic press over a $300 \mathrm{~mm}$ flatten plate. Laminate A was produced by stacking 16 plies of SRPP1 and heated to about $160^{\circ} \mathrm{C}$. Laminate $\mathrm{G}$ to $\mathrm{J}$ was produced by stacking SRPP1 between two outer layers of GFPP. The results of mechanical testing have shown that hybridizing the GFPP and SRPP has combined the strength and stiffness of the GFPP and the impact resistance and low density of the SRPP1. Increasing the volume fractions of the SRPP increases the energy absorbing characteristics of the composite and increasing the volume fraction of the GFPP increases the flexural modulus of the composite.

Sabiedet al. [8] Study the elastic properties and notch sensitivity of untreated jute fabric and jute-glass fabric reinforced polyester hybrid composites using analytical and experimental approach. Elastic properties were determined using the hybrid rule of mixture and classical lamination theory. The results of the investigation reveal that jute composites undergo more transverse strain and less longitudinal strain than the jute-glass reinforced hybrid composite.

The performance of short hemp fiber and glass fiber reinforced polypropylene (PP) hybrid composite was analyzed by Pathapulakkalet al. [9]. Mechanical, water absorption and thermal properties were the main focus of the research. Test samples were produced using an injection molding process. The results showed that hybridization with glass fiber improved the properties of the composite. The flexural strength and modulus was $101 \mathrm{GPA}$ and 5.5GPA respectively. The percentage by weight of reinforcement was $25 \%$ hemp fiber and $15 \%$ glass fiber. The thermal stability of hemp/PP and hemp/Glass/PP was investigated with thermo gravimetric analysis. Both hemp and hybrid composite showed degradation between $250^{\circ} \mathrm{C}-400^{\circ} \mathrm{C}$ and was due to the decomposition of cellulose and hemi-cellulosic components of the natural fibers. The water absorption of PP was $0.4 \%$ and is negligible compared to the water absorption of $40 \%$ hemp fiber reinforced PP (8.73\%). The addition of glass fiber into the mixture decreased the equilibrium moisture content significantly. This was because of the hydrophilic behavior of the natural fibers from the matrix and the glass fiber having a little effect on the amount of water absorbed.

The mechanical behavior of banana fiber based bio hybrid composite was investigated using different material compositions [10]. Banana fiber and silica were used as reinforcing materials in an epoxy matrix. HY 951 hardener was used as an additive. Different proportions of banana fiber, silica and epoxy resin were prepared by mechanical stirring at 3000 RPM. The mixture was placed in an electric furnace for two hours at a temperature of $90 \pm 10^{\circ} \mathrm{C}$. The mixture was then removed from the furnace and allowed to cool to a temperature of about $45^{\circ} \mathrm{C}$. After the mixture has attained a temperature of about $45^{\circ} \mathrm{C}$, hardener 951 was mixed together with the banana/silica mixture to produce a viscous solution which was further remixed using the high speed mechanical stirrer. The test samples produced were subjected to mechanical testing. The ultimate tensile strength of the banana/silica composite is 27.618 MPawhich is lower compared to the neat epoxy resin which has an ultimate strength of $47.790 \mathrm{MPa}$. The ultimate compressive strength of $2 \mathrm{with} \%$ of silica and $10 \mathrm{wt} \%$ of banana fire was found to be $63.202 \mathrm{MPa}$ which is lower compared to the ultimate strength of the neat epoxy resin.

From the studies conducted above on woven natural fiber hybrid composite, there is no much emphasis on developing a hybrid composite using natural fiber and thermoplastic fiber in a thermoplastic matrix. The effect of fiber orientation on the mechanical properties of the unidirectional hybrid composite was only focused on $0^{\circ} / 90^{\circ}$ orientation. This paper focuses on predicting the tensile properties of kenaf/PET fiber reinforced POM hybrid laminate composite at three different orientations with the aim of achieving high strength and high elastic modulus.

\section{Materials And Methods}

The selection of Kenaf fiber for this analytical design was based on mechanical properties and thermal stability. Polyethylene terephthalate (PET) fiber was selected as the second reinforcement because of good thermal stability with other thermoplastics. The matrix selected was polyoxymethylene (POM) because of having good mechanical properties and lower melting temperature as compared to PET.

\subsection{Design calculation requirements}

1. Volume fraction of the fiber and the matrix

2. Critical volume fraction of the high elongation fiber 
3. Ultimate strength of the fibers and the matrix

4. Fiber elongation at break

5. Orientation of the fibers

6. Specific gravity of the fiber and the matrix

\subsection{Rule of mixtureof hybrid composite}

By the rule of mixtures, the modulus of a composite is defined as the combination of the modulus of the fiber and the modulus of the matrix that are related to the volume fractions of the constituent materials [11]. If subscript $\mathrm{f}$ and $\mathrm{m}$ denotes fiber and matrix, then the rule of mixture equation will be given by equation 1 :

$$
E_{c}=E_{f} V_{f}+E_{m} V_{m}=E_{f} V_{f}+E_{m}\left(1-V_{f}\right) \ldots \ldots 1
$$

$E_{c}$ Is the modulus of elasticity of the composite material. According to the rule of mixtures, the volume fraction of the fiber and the volume fraction of the matrix must be unity as in equation 2 :

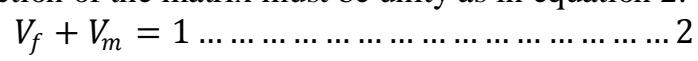

In an aligned two fiber composite (hybrid composite), the rule of mixtures can be expanded as in equation 3 where subscript $\mathrm{a}$ and $\mathrm{b}$ indicates each of the fiber species [11].

$$
\begin{gathered}
E_{H}=E_{a} V_{a}+E_{b} V_{b}+E_{m}\left(1-V_{a}-V_{b}\right) \ldots \ldots \ldots .3 \\
V_{a}+V_{b}+V_{m}=1 \ldots \ldots \ldots \ldots \ldots \ldots \ldots \ldots \ldots \ldots .4
\end{gathered}
$$

In practice, the contribution of the matrix to the overall strength of the composite is negligible and is ignored [12]:

$$
\begin{aligned}
& E_{H}=E_{a} V_{a}+E_{b} V_{b} \ldots \ldots \ldots \ldots \ldots \ldots \ldots \ldots \ldots 5 \\
& \sigma_{H}=\sigma_{a} V_{a}+b V_{b} \ldots \ldots \ldots \ldots \ldots \ldots \ldots \ldots \ldots \ldots 6
\end{aligned}
$$

If the volume fraction of the high elongation fiber is high in the composite and load is applied, the low elongation fibers will experience multiple failures before the failure of the high elongation fibers is reached. It is assumed that the low elongation fibers did not make any contribution in the composite. From the Rule of mixture, the hybrid composite strength is therefore [13]:

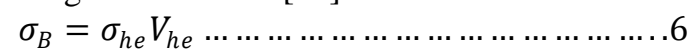

When a high volume fraction of the low elongation fiber is added, the composite will still fail and the entire load will be carried by the high elongation fibers. The hybrid composite strength is given by equation 7 [13].

$$
\sigma_{B}=\sigma_{h e} V_{h e}+\sigma_{l e} V_{l e} \ldots \ldots \ldots \ldots \ldots \ldots \ldots \ldots .7
$$

Where $\sigma_{h e}$ is the strength of the high elongation fiber, $\sigma_{l e}$ Is the strength of the low elongation components $V_{h e} V_{l e}$ are the volume fractions of the high elongation and low elongation components respectively. The critical volume fraction of the high elongation component is given by equation 8 [13]:

$$
V_{\text {crit }}=\frac{\sigma_{l e}}{\sigma_{l e}+\sigma_{h e}-\varepsilon_{l e} E_{h e}} \ldots \ldots \ldots \ldots \ldots \ldots \ldots .8
$$

The hybrid composite strength at fiber fracture strain is given by equation 9 :

Definition of symbols:

$$
\sigma_{\text {min }}=\left(1-V_{\text {crit }}\right) E_{l} \varepsilon_{l} \ldots \ldots \ldots \ldots \ldots \ldots \ldots \ldots \ldots
$$

$\mathrm{E}_{1}=$ Modulus of Elasticity in the longitudinal direction

$\mathrm{E}_{2}=$ Modulus of Elasticity in the transverse direction

$\mathrm{G}_{12}=$ Shear modulus of ply

$\mathrm{G}_{\mathrm{m}}=$ Shear modulus of the matrix

Golf $=$ Shear Modulus of the fiber

$\alpha_{1}{ }^{\mathrm{T}}=$ Longitudinal Coefficient of Thermal Expansion= CTE1

$\alpha_{2}{ }^{\mathrm{T}}=$ Transverse Coefficient of Thermal Expansion= CTE2

$\mathrm{V}_{12}=$ poisons ratio

$\tau=$ Shear Stress

\subsection{Equations for Ply properties}

The equations for calculating ply properties are shown below [14, 15]:

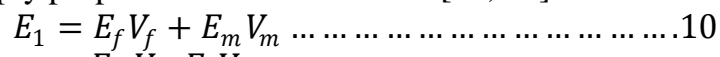

$$
\begin{aligned}
& E_{2}=\frac{E_{m} V_{f+} E_{f} V_{m}}{E_{m} E_{f}}
\end{aligned}
$$




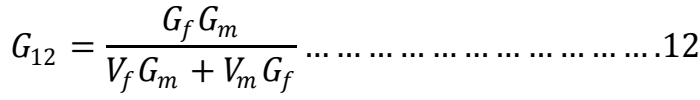

$$
\begin{aligned}
& v_{12}=v_{f} V_{f}+v_{m} V_{m} \ldots \ldots \ldots \ldots \ldots \ldots \ldots \ldots \ldots .13 \\
& \alpha_{1}^{T}=\frac{\alpha_{m}^{T} E_{m} V_{m}+\alpha_{f}^{T} E_{f} V_{f}}{E_{1}} \ldots \ldots \ldots \ldots \ldots \ldots \ldots 14 \\
& \alpha_{2}^{T}=\alpha_{m}^{T} V_{m}\left(1+v_{m}\right)+\alpha_{f}^{T} V_{f}\left(1+v_{f}\right)-v_{12} \alpha_{1}^{T} . .15 \\
& \rho_{c}=\rho_{f} V_{f}+\rho_{m} V_{m} \ldots \ldots \ldots \ldots \ldots \ldots \ldots \ldots \ldots \ldots . .16 \\
& \sigma_{\text {cmax }}=2\left[V_{f}+\left(1-V_{f}\right) \frac{E_{m}}{E_{f}}\right] \sqrt{\frac{V_{f} E_{m} E_{f}}{3\left(1-V_{f}\right)}}
\end{aligned}
$$

\begin{tabular}{|c|c|c|c|}
\hline & Kenaffiber & $\begin{array}{l}\text { PET } \\
\text { fiber }\end{array}$ & $\begin{array}{c}\text { POM } \\
\text { matrix }\end{array}$ \\
\hline $\begin{array}{l}\text { Tensile strength } \\
\text { (GPa) }\end{array}$ & $\overline{0.6}$ & 1.01 & 0.06 \\
\hline $\begin{array}{l}\text { Compressive } \\
\text { strength (GPa) }\end{array}$ & 0.057 & 0.08 & 0.031 \\
\hline Modulus (GPa) & 40 & 9 & 3.5 \\
\hline Fiber diamer (mm) & 0.2 & 0.02 & - \\
\hline Density $\left.\left(\mathrm{g} / \mathrm{cm}^{3}\right)\right)$ & 1.3 & 1.38 & 1.42 \\
\hline $\begin{array}{l}\text { Shearmodulus } \\
\text { (GPa) }\end{array}$ & - & 2 & 0.93 \\
\hline Poisson's ratio & 0.2 & 0.404 & 0.35 \\
\hline Thermal expansion & - & 80 & 104 \\
\hline $\begin{array}{l}\text { coefficient (/K) } \quad x \\
10^{-6}\end{array}$ & - & - & \\
\hline Shear strength & - & - & 0.062 \\
\hline
\end{tabular}

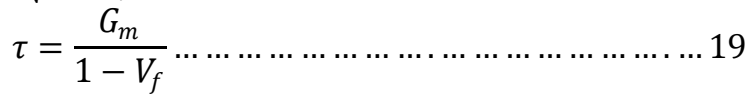

$$
\begin{aligned}
& \sigma_{C}=\sigma_{f 1} V_{f 1}+\sigma_{f 2} V_{f 2}+\sigma_{m} V_{m} \ldots \ldots \ldots \ldots \ldots \ldots \ldots 20
\end{aligned}
$$

Table 1 shows the material properties used in calculating the ply properties [16, 17, and 18].

Table 1: Materials data for determining Ply Properties

\section{Results And Discussion}

The analytical results obtained for single layer commingledkenaf/PET hybrid composites are shown in table 2 using equation 20.

Table 2: Properties of commingled Kenaf/PET Reinforced POM

\begin{tabular}{cc}
\hline Volume fractions & $\begin{array}{c}\text { Composite } \\
\text { strength } \\
(\mathbf{G P a})\end{array}$ \\
\hline $\boldsymbol{V}_{\boldsymbol{K}}=\mathbf{0 . 9}, \boldsymbol{V}_{\boldsymbol{P E T}}=\mathbf{0 . 1}$ & 0.641 \\
$\boldsymbol{V}_{\boldsymbol{K}}=\mathbf{0 . 8}, \boldsymbol{V}_{\boldsymbol{P E T}}=\mathbf{0 . 2}$ & 0.682 \\
$\boldsymbol{V}_{\boldsymbol{K}}=\mathbf{0 . 7}, \boldsymbol{V}_{\boldsymbol{P E T}}=\mathbf{0 . 3}$ & 0.723 \\
$\boldsymbol{V}_{\boldsymbol{K}}=\mathbf{0 . 6}, \boldsymbol{V}_{\boldsymbol{P E T}}=\mathbf{0 . 4}$ & 0.764 \\
$\boldsymbol{V}_{\boldsymbol{K}}=\mathbf{0 . 5}, \boldsymbol{V}_{\boldsymbol{P E T}}=\mathbf{0 . 5}$ & 0.805 \\
$\boldsymbol{V}_{\boldsymbol{K}}=\mathbf{0 . 4}, \boldsymbol{V}_{\boldsymbol{P E T}}=\mathbf{0 . 6}$ & 0.846 \\
$\boldsymbol{V}_{\boldsymbol{K}}=\mathbf{0 . 3}, \boldsymbol{V}_{\boldsymbol{P E T}}=\mathbf{0 . 7}$ & 0.887 \\
$\boldsymbol{V}_{\boldsymbol{K}}=\mathbf{0 . 2}, \boldsymbol{V}_{\boldsymbol{P E T}}=\mathbf{0 . 8}$ & 0.928 \\
$\boldsymbol{V}_{\boldsymbol{K}}=\mathbf{0 . 1}, \boldsymbol{V}_{\boldsymbol{P E T}}=\mathbf{0 . 9}$ & 0.969 \\
\hline
\end{tabular}

Figure 1.0 shows the contribution of Kenaf fiber and PET fiber in raising the hybrid composite strength. The point of intersection of the two lines is the critical volume fraction of the high elongation component which defines the hybrid composition of minimum strength. 


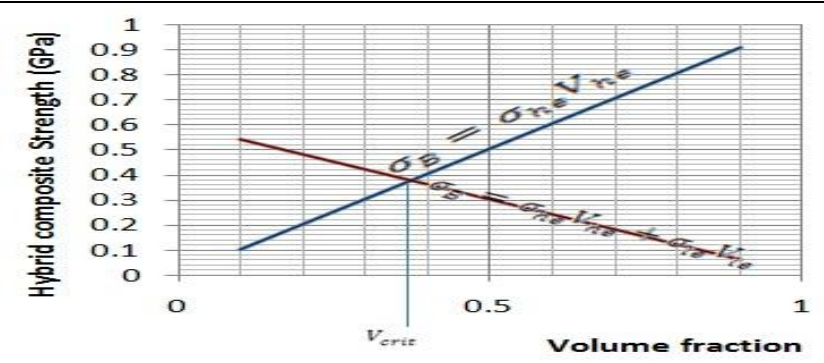

Figure 1.0 Hybrid composite strength Vs. Volume fraction

The critical volume fraction was calculated from equation 8 which gave 0.39 corresponding to the value on the graph.

The table below shows the results of Ply properties for each layer in the hybrid composite.

Table 3: Ply properties of the composite

\begin{tabular}{ccc}
\hline Properties & $\begin{array}{c}\text { KENAF/POM } \\
\mathbf{V}_{\mathbf{f}}(\mathbf{4 0} / \mathbf{6 0})\end{array}$ & $\begin{array}{c}\text { PET/POM } \\
\mathbf{V}_{\mathbf{f}}(\mathbf{4 0} / \mathbf{6 0})\end{array}$ \\
\hline $\mathbf{E 1}(\mathbf{G P a})$ & 18.1 & 5.7 \\
$\mathbf{G 1 2}(\mathbf{G P a})$ & 1.5 & 1.18 \\
$\boldsymbol{\alpha}_{\mathbf{1}}^{\mathbf{T}} \mathbf{x 1 0 ^ { - 6 }} / \mathbf{K}$ & 12.1 & 88 \\
$\boldsymbol{\alpha}_{\mathbf{2}}^{\mathbf{T}} \mathbf{x 1 0 ^ { - 6 }} / \mathbf{K}$ & 80.76 & 96 \\
$\mathbf{T}(\mathbf{G P a})$ & 1.55 & 1.55 \\
$\boldsymbol{\sigma}_{\mathbf{m a x}}(\mathbf{G P a})$ & 5.6 & 0.492 \\
$\mathbf{P l y}$ thickness $(\mathbf{m m})$ & 2.0 & 2.0 \\
$\boldsymbol{\rho}\left(\mathbf{g} / \mathbf{c m}^{\mathbf{3}}\right)$ & 1.37 & 1.404 \\
$\boldsymbol{\sigma}_{\mathbf{x t}}(\mathbf{M P a})$ & 276 & 440 \\
$\boldsymbol{\sigma}_{\mathbf{x c}}(\mathbf{M P a})$ & 41.4 & 50.6 \\
$\boldsymbol{\sigma}_{\mathbf{y t}}(\mathbf{M P a})$ & 60 & 60.2 \\
$\boldsymbol{\sigma}_{\mathbf{y c}}(\mathbf{M P a})$ & 60 & 60.2 \\
\hline
\end{tabular}

The engineering and thermal properties of the laminate using LAMINATOR application software based on classical lamination theory is given in table 4, 5, 6 and 7 respectively.

Table 4: Engineering and Thermal properties

\begin{tabular}{lcccccc}
\hline & $\begin{array}{c}\mathbf{E}_{\mathbf{1}} \\
(\mathbf{G P a})\end{array}$ & $\begin{array}{c}\mathbf{E}_{\mathbf{2}} \\
(\mathbf{G P a})\end{array}$ & $\begin{array}{c}\mathbf{G}_{12} \\
(\mathbf{G P a})\end{array}$ & $\begin{array}{c}\mathbf{V}_{\mathbf{1 2}} \\
(\mathbf{G P a})\end{array}$ & $\begin{array}{c}\text { CTE1 } \\
(/ \mathbf{K}) \\
\mathbf{1 0}^{-\mathbf{6}}\end{array}$ & $\begin{array}{c}\text { CTE1 } \\
(/ \mathbf{k}) \\
\mathbf{1 0}^{-\mathbf{6}}\end{array}$ \\
\hline KN/POM & 18.1 & 0.18 & 1.5 & 0.29 & 12.1 & 80.7 \\
PET/POM & 5.7 & 0.21 & 1.18 & 0.37 & 88 & 96 \\
\hline
\end{tabular}

The longitudinal modulus of the KN/POM and PET/POM layer from table 4 is seen to be higher than the transverse modulus. The fiber modulus dominates the composite modulus in the fiber direction while the matrix modulus dominates the composite modulus in the transverse direction.

The stacking sequence of the hybrid composite is shown in table 4with six ply arrangements.

\begin{tabular}{|c|c|c|c|c|c|c|c|}
\hline \multicolumn{3}{|c|}{ Ply } & \multicolumn{3}{|c|}{$\mathrm{Z}$ coordinates in laminate } & \multirow{2}{*}{$\begin{array}{c}\mathbf{T} \\
(\mathbf{m m}) \\
\end{array}$} & \multirow{2}{*}{$\begin{array}{l}\text { Density } \\
\text { (kg/m3) }\end{array}$} \\
\hline $\mathrm{S} / \overline{\mathrm{N}}$ & Name & Angle & Top & Middle & Bottom & & \\
\hline 1. & KN/POM & 0 & -6.2 & -5.2 & -4.2 & 2.0 & 1.37 \\
\hline 2. & $\begin{array}{l}\text { PET- } \\
\text { f/POM }\end{array}$ & 45 & -4.2 & -3.2 & -2.2 & 2.0 & 1.40 \\
\hline 3. & KN/POM & 90 & -2.2 & -1.2 & -0.2 & 2.0 & 1.37 \\
\hline 4. & $\begin{array}{l}\text { PET- } \\
\text { f/POM }\end{array}$ & 90 & -0.2 & 0.8 & 1.8 & 2.0 & 1.4 \\
\hline 5. & KN/POM & 45 & 1.8 & 2.8 & 3.8 & 2.0 & 1.37 \\
\hline 6. & PET/POM & 0 & 3.8 & 4.8 & 5.8 & 2.0 & 1.40 \\
\hline
\end{tabular}




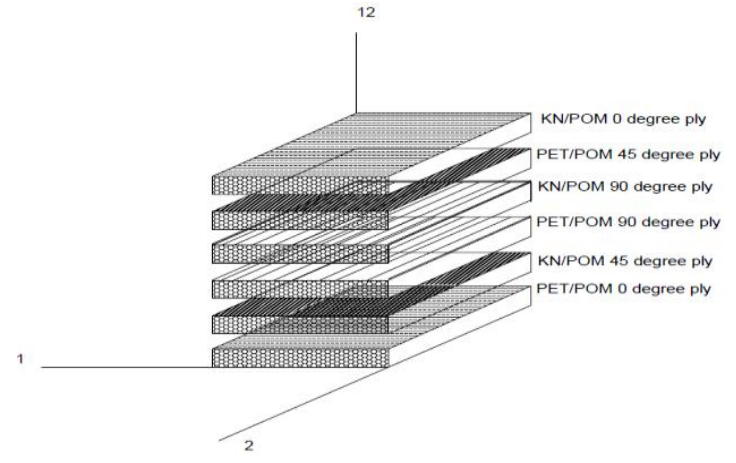

Figure 2.0 hybrid laminate stacking sequence.

The stiffness, coupling coefficient and thermal properties are given in Table 6.

Table 6: Laminate Stiffness, Coupling Coefficient andThermal Properties

\begin{tabular}{|c|c|c|c|c|c|}
\hline \multicolumn{5}{|c|}{ Laminate stiffness properties } & \\
\hline $\mathrm{E}_{\mathrm{X}}(\mathrm{GPa})$ & $\mathrm{E}_{\mathrm{Y}}(\mathrm{GPa})$ & $\begin{array}{c}\mathrm{G}_{\mathrm{XY}}(\mathbf{G P} \\
\text { a) }\end{array}$ & $\mathrm{E}_{\mathrm{XB}}(\mathrm{GPa}$ & $\mathrm{E}_{\mathrm{YB}}(\mathrm{GPa})$ & \\
\hline 4.0 & 4.81 & 1.43 & 7.53 & 1.303 & \\
\hline \multicolumn{6}{|c|}{ Laminate coupling coefficient ( Poisson and shear coupling) } \\
\hline vXY & vYX & $\mathrm{nXY}, \mathrm{X}$ & $\mathrm{nXY}, \mathrm{Y}$ & $\mathrm{nX}, \mathrm{XY}$ & $\mathrm{nY}, \mathrm{XY}$ \\
\hline 0.026 & 0.031 & -0.510 & -0.522 & -0.180 & -0.156 \\
\hline \multicolumn{6}{|c|}{ Thermal properties } \\
\hline & $\begin{array}{l}\text { CTEX } \\
(/ \mathrm{k})\end{array}$ & $\operatorname{CTEY}(/ \mathrm{k})$ & \multicolumn{2}{|c|}{ CTEXY $(/ \mathrm{k})$} & \\
\hline & $3.9 \times 10^{-5}$ & $3.27 \times 10^{-5}$ & $-5.23 x$ & & \\
\hline
\end{tabular}

The theoretical results of the laminate stiffness properties above may vary with the experimental results due to poor interfacial adhesion between the fiber and the matrix and disorientation of the fibers from the principal material axis.

The laminate strengths for first ply failure under unidirectional loading are given in table 7.

\begin{tabular}{lccccc} 
Table 7: Laminate Strength for First Ply Failure underUnidirectional Loading \\
$\begin{array}{l}\text { Failure } \\
\text { theory }\end{array}$ & $\begin{array}{c}\text { X-axis } \\
\text { Tens. }\end{array}$ & $\begin{array}{l}\text { X-axis } \\
\text { Comp. }\end{array}$ & $\begin{array}{l}\text { Y-axis } \\
\text { Tens. }\end{array}$ & $\begin{array}{l}\text { Y-axis } \\
\text { Comp. }\end{array}$ & Shear \\
\hline $\begin{array}{l}\text { Maximum } \\
\text { stress (GPa) }\end{array}$ & 0.109 & -0.0168 & 0.0792 & -0.0121 & 0.0341 \\
$\begin{array}{l}\text { Maximum } \\
\text { strain }\end{array}$ & 0.11 & -0.0168 & 0.079 & -0.0121 & 0.034 \\
$\begin{array}{l}\text { Tsai-Hill } \\
\text { Hoffman }\end{array}$ & 0.11 & -0.0168 & 0.0793 & -0.0121 & 0.0344 \\
Tsai-Wu & 0.11 & -0.0168 & 0.0794 & -0.0121 & 0.0342 \\
\hline
\end{tabular}

The stresses above showed the laminate stress after first ply failure when a load is applied along the fiber direction.

The $0^{0}$ ply orientationsare suitable to carry loads in the longitudinal direction. The $90^{\circ} \mathrm{ply}$ orientationsare suitable to react to load in the transverse direction and the $45^{0}$ ply orientations are to respond to shear loads. The $90^{\circ}$ ply orientations immediately above and below the midplane is to minimize warpage and interlaminar shear within the laminate. The laminate stiffness matrix is shown below. 
Extensional stiffness matrix [A] Coupling stiffness matrix [B] (GPa-mm)

$\left(\mathrm{GPa}-\mathrm{mm}^{2}\right)$
$\left\{\begin{array}{ccc}66 & 7.4 & 11.7 \\ 7.4 & 66 & 11.7 \\ 11.7 & 11.7 & 22.7\end{array}\right\}\left\{\begin{array}{ccc}-103 & 16.8 & 18.63 \\ 16.8 & -4.1 & 18.6 \\ 18.6 & 18.6 & 14.7\end{array}\right\}$

Coupling stiffness matrix [B] Bending stiffness matrix [D] $\left(\mathrm{GPa}-\mathrm{mm}^{2}\right)$ $\left(\mathrm{GPa}-\mathrm{mm}^{3}\right)$

$\left\{\begin{array}{ccc}-103 & 16.8 & 18.63 \\ 16.8 & -4.1 & 18.6 \\ 18.6 & 18.6 & 14.7\end{array}\right\}\left\{\begin{array}{ccc}1373 & 71.2 & 109.4 \\ 71.2 & 247 & 109.4 \\ 109.4 & 109.4 & 254.8\end{array}\right\}$

Inverse of the stiffness matrix

$$
\begin{gathered}
\left\{\begin{array}{ccc}
0.02 & -0.0005 & -0.0104 \\
-0.0005 & 0.017 & -0.009 \\
-0.01 & -0.009 & 0.058
\end{array}\right\}\left\{\begin{array}{ccc}
0.0018 & -0.00051 & -0.0014 \\
-0.0001 & 0.0016 & -0.0013 \\
-0.0012 & -0.0034 & -0.00011
\end{array}\right\} \\
\left\{\begin{array}{ccc}
0.0018 & -0.00051 & -0.0014 \\
-0.0001 & 0.0016 & -0.0013 \\
-0.0012 & -0.0034 & -0.00011
\end{array}\right\}\left\{\begin{array}{ccc}
0.00092 & -0.00011 & -0.00039 \\
-0.00011 & 0.0053 & -0.0021 \\
-0.00039 & -0.0021 & 0.0052
\end{array}\right\}
\end{gathered}
$$

From the stiffness matrix above, the hybrid composite shows an anti-symmetric angle ply laminate behavior even though the stacking sequence is symmetric with the middle surface. This is because the coupling stiffness matrix [B] has a nonzero value [16]. This shows that bending-stretching coupling will be experienced by the material which is not common with conventional symmetric laminates. The inverse of the stiffness matrix gives the mid-plane strains in $\mathrm{x}, \mathrm{y}$ and $\mathrm{x}-\mathrm{y}$ axis.

The chart in figure 3.0 showsthe contribution of fiber modulus in raising the composite modulus.

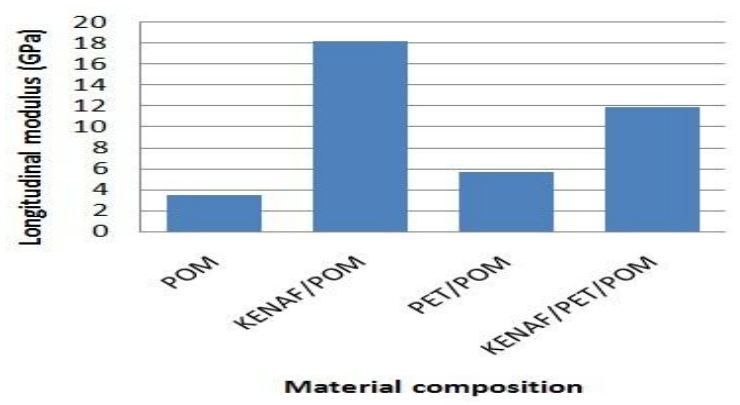

Figure 3.0 Elastic modulus of composites

When only kenaf is reinforced with POM, the longitudinal modulus is higher compared to a hybrid composite consisting of both kenaf and PET. This is because kenaf high modulus of elasticity contributes more in raising the tensile modulus of the composite.

\section{Conclusion}

The strength of the hybrid laminate composite depends largely on the high elongation fiber (PET fiber), while the modulus of elasticity depends on the contribution of the low elongation component of the composite (Kenaf/POM). The thermal expansion coefficient of the hybrid laminate is higher than the individual components of the hybrid composite. The three different fiber orientations give the material's ability to respond to loads in longitudinal direction, transverse direction and also respond to shear loads. The significance of this analysis confirms that both high strength and high modulus of elasticity can be achieved when two reinforcements of different elongations are used in a thermoplastic matrix. 


\section{Predicting The Tensile Properties Of Woven Kenaf/PET Fibre Reinforced POM Hybrid Composite}

\section{References.}

[1] G. H. Fan, L. Geng, Z. H. Lai, G. S. Wang “preparation of hybrid composite based on $\mathrm{BaPb}_{3}+\mathrm{Al}_{18} \mathrm{~B}_{4} \mathrm{O}_{33} / 6061 \mathrm{Al}$ system", Journals of Alloys and Compounds Volume 482, Issue 1-2, PP:512-516, 2009.

[2] A. Panigrahi, S. R. Mallick " characterization of hybrid FRP composite with hydrothermal exposure under varied ambient conditions" Department of metallurgical and materials engineering, National Institute of Technology Rourkela, PP: 8-10, 2008

[3] JEC, 'high performance bio composites' JEC composite magazines No. 55, 2010.

[4] U.A. Khashaba and M. A. Seif "Journal of Composite Structures" 74PP: 440, 2006.

[5] W. L. Lai and M. Mariatti, “journal of Reinforced Plastics” 27 PP: 925, 2008.

[6] M. A. Maleque, F. Y. Belal and S.M. Sapuan,The Arabian Journal for ScienceAnd engineering 32 PP: $359,2007$.

[7] H. T. Kuan, W. Cantwell and H. MdAkil, The mechanical properties of hybrid composite Based on self reinforced polypropylene' Malaysian Polymer journal Vol. 4 No. 2 PP: 71- 802009.

[8] K. Sabeel Ahmed, S. Vijayarangan\& A.C.B. Naidu, Journal of materials and design, 28 PP: 2287, 2007.

[9] S. Panthapulakkal, \& M. Sain, "Injection-molded short Hemp fibre/Glass fibre reinforced polypropylene hybrid compositesMechanical, Water absorption and thermal properties" Journal of Applied Polymer Science Vol. 103, Wiley Periodicals, Inc. PP: 2432-2441, 2006.

[10] Singh V. K, Gope P. C. , ChauhanSakshi\&Bisht Deepak Singh "Mechanical properties of banana fibre based Bio hybrid composite" J. Mater. Environ Sci. 3 (1), PP: 185-194, 2012.

[11] M. Jacob, L. A. Pothan\& S. Thomas "hybrid composite "internet address: http://researchspace.csir.co.za/dspace/bitstream/10204/3600/1/John_d2_2009.pdf

[12] D. Short \& J. Summerscales“ New theoretical approach to the strength of fibre composite hybrid materials" $13^{\text {th }}$ BPF reinforced plastic congress, Brighton, Paper 53 PP: 225-229, 1982.

[13] Bryan Harris, "Engineering Composite Materials", IOM communications Limited, Second edition, PP: 6, 120-123, 1999.

[14] F. Gibson, "Principles of composite materials mechanics" Taylor \& Francis Group, CRC Press Boca Raton PP: 83-126, 2007

[15] R. M. Jones "Mechanics of composite materials" Taylor \& Francis, Philadelphia USA PP: 121-200, 1999.

[16] G. Cicala, G. Cristaldi, G. Recca and A. Latteri. Composites Based on Natural Fiber Fabrics, Woven Fabric Engineering, $\begin{array}{lllll}\text { PolonaDobnikDubrovski } & \text { (Ed.), } & \text { ISBN: } & 978-953-307-194-7, & \text { (2010)InTech, Available from: }\end{array}$ http://www.intechopen.com/books/woven-fabric-engineering/composites-based-on-natural-fibre-fabrics

[17] Phoinex Technologies "PET properties 2008"Available from:http://www.phoenixtechnologies.net/why/PET\%20Properties\%202008.pdf

[18] MATBASE "Properties of POM" Available from:http://www.matbase.com/material/polymers/engineering/pom.hom/properties

[19] R. F. Gibson, "Principles of composite material mechanics" CRC press Boca Raton US PP: 261-300, 2007 